\title{
ANALYSIS OF COMMUNICATION OF LATGALE'S LARGEST MUNICIPALITIES ON THE INSTAGRAM NETWORK - A COMPARISON OF DAUGAVPILS CITY AND REZEKNE MUNICIPALITY
}

\author{
Karlis Poznakovs \\ Mg. sc. soc., laboratory assistant, Rezekne Academy of Technologies, Rezekne, Latvia, \\ e-mail: karlis.poznakovs@gmail.com
}

Received: 23 September 2020 / Revised: 1 October 2020 / Accepted: 15 October 2020 /

Published: 30 November 2020

\begin{abstract}
The topic of the paper is "Analysis of Communication of Latgale's Largest Municipalities on the Instagram Network - a Comparison of Daugavpils City and Rezekne Municipality". The paper researches the communication of the largest city and municipality of Latgale region - Daugavpils and Rezekne - on the Instagram network in the period from registration.

The aim of the paper is to find out how and for what purposes the municipalities of Daugavpils city and Rezekne use the social medium "Instagram" and what results the communication via this channel have been achieved.

The paper consists of two parts - theoretical and empirical. The theoretical part summarizes and analyses theory on the history and development of the social network Instagram, as well as its impact on corporate communication of companies and institutions.

The empirical part contains a comparative analysis of communication of Daugavpils city and Rezekne municipality on the Instagram network, analysing the posted information and feedback from network users. Content analysis is used as a research method to achieve the aim.
\end{abstract}

Keywords: Social networks, Instagram, corporate communication, municipal communication.

JEL code: M31.

\section{Introduction}

The rapid development of technology has affected not only our lifestyle but also changed the way organizations develop their communication. More and more people are using the opportunities provided by the Internet to find the information they need. In 2020, the number of social network users in the world exceeded 3.6 billion (statista.com) and they have become one of the most important communication tools for organizations, so institutions must follow the information gathering habits of citizens and adapt by creating profiles on social networks.

Instagram is becoming more and more popular among social networks. It is currently the sixth most popular social network in the world in terms of the number of users. The uniqueness of the social network is that it is 
primarily intended for use on smartphones, not computers, therefore it has a highly visual content, and organizations need to find ways to present their information in photo or video format. Municipalities of Latgale region are also no exception, which create profiles on the Instagram network in order to address local residents and compete with other municipalities for attracting tourists and investors, as well as to improve the public image. Among these municipalities, there is also the largest city of Latgale, Daugavpils, and the largest municipality - Rezekne municipality.

Although almost every municipality has a profile on Instagram, little research has been done so far on how municipalities organize communication on this network and what results it provides. Therefore, the aim of the paper is to find out how and for what purposes municipalities of Daugavpils city and Rezekne municipality use the social medium "Instagram" and what results the communication via this channel have been achieved.

In order to achieve the aim, several tasks are set:

- to study the academic literature on corporate communication on social media and the social medium "Instagram" as a corporate communication channel;

- to study and analyse the communication of Daugavpils city and Rezekne municipality via the "Instagram" channel;

- to summarize and analyse the obtained research results;

- to draw conclusions about the results obtained during the research process.

To achieve the aim, a quantitative and qualitative content analysis was performed and categories to analyse Instagram content were developed.

Instagram is the sixth largest social network in the world in terms of the number of users, also playing an important role in the communication of companies and institutions.

\section{Role of the Instagram Network in Communication}

Instagram is one of the most popular social networks in the world, where photos or videos are being published. The social network was launched in 2010 and was initially popular among users as a tool for reflecting on everyday life, but it is an important aspect of corporate communication and branding in 2020.

Instagram is fully designed for publishing and sharing videos and photos. Instagram allows users to tag their posted photos with keywords or hashtags, which makes it more efficient and easier to search for images and videos by their subject (Tiggemann, Zaccardo, 2016).

While most social networks were originally created for use on a computer, Instagram is designed exclusively for users of smart devices 
(Neher, 2013). The growth of the number of the social network's users was faster than the previously developed social networks - the number of users reached 1 million after a month of operation, while 150 million users had registered in it after 3 years of operation (Turri, Smith, Kemp, 2013).

The possibilities of placing content on the Instagram network are limited by its tools, so companies and institutions need to find a way to turn the message into a visual way. Institutions can use the Instagram network for several purposes:

- Communication with inhabitants

- Promotion of citizen participation

- Promotion of transparency of the institution's work

- Analysis of public opinion and activities

- Image building and strengthening (Khan, 2017).

As mentioned above, Instagram is a social network where the content is mostly visual, so companies and institutions need to find a way to attract the attention of the target audience, thus four ways to attract the attention of network users are identified:

A. Goodman, a scientist, defined four principles of attracting attention. In his opinion, the first is a personal approach. When planning a campaign, the power of personal influence must not be forgotten. The second is unexpectedness. People like learning new things and sharing them with friends. It is important to involve the audience by creating curiosity and try to offer a new perspective on already known things. The third is visibility. It is good not to tell, but to show. "Photos and videos speak louder than a million words." It is important to supplement the ideas with symbolic images/graphics. The fourth and, in his opinion, the most important thing is to address the feelings of the audience. The campaign should be designed in such a way that it touches all possible feelings (sight, hearing, taste, touch). Music should be used to evoke deep emotions (Goodman, 2003).

The content of Instagram consists of tools such as hashtags mentions, likes, descriptions, geotags, which are similar to other social networks, but their function may differ. For example, on Twitter, they are mostly used to gather conversations, while on Instagram they distribute content as well as bring communities together (Caliandro, Graham, 2020).

Many institutions and companies use Instagram not only for communication but also for brand promotion.

Moreover, social media also provide the marketers with an easier way to understand their customers. In the case of Instagram, leaving comments and receiving comments on the photo posts can gain more feedback from the customers on the product. Followers are often interested to see the interaction between the organization and the users, so being attentive to the comments would help in improving the relationship with customers. 
Furthermore, Instagram has included a function known as direct messaging. This function could give the VIP customers another way to communicate and interact with the organization (Lim, Yazdanifard, 2014).

\section{Methodology}

In order to obtain the most accurate data for the research, the content analysis of Daugavpils city and Rezekne municipality Instagram pages was carried out according to the quantitative and qualitative categories. The categories of analysis were developed based on Instagram's publishing tools.

The communication analysis of both municipalities was examined in the following quantitative categories, which allowed us to compare the statistical results of both profiles:

- Number of posts - allows us to measure the quantity of posts;

- Date of first publication - allows us to calculate the regularity of posts;

- Number of followers - allows us to measure the effectiveness of the communication;

The methodology also included several qualitative categories, which allowed us to compare the content of both profiles:

- Type of publications - the posts were examined by their type, for example, video, photo, poster etc.;

- Use of languages - allows us to analyze the target audience;

- Hashtags - allows us to analyze the target audience and theme of the post;

- Quality of pictures - the quality of pictures was analyzed in three categories: low, medium and high.

- Additional tools - the use of additional tools such as Instagram stories, geolocation etc.

\section{Analysis of Communication of Daugavpils City and Rezekne Municipality}

Within the framework of the research, the Instagram profiles of the largest Latgale city, Daugavpils, and the largest municipality, Rezekne, were analysed since the first publication in order to measure the regularity of publications.

The profile of Daugavpils city was registered on October 11, 2015, and 796 photos have been published in almost 3 years, thus it can be concluded that the content is being updated regularly, while Rezekne municipality registered on Instagram on October 2, 2018, and 109 photographs have been posted without systematic regularity. 
The city of Daugavpils has chosen tourists as the main target audience, which already appears in the profile name (daugavpils.travel), as well as in the most frequently used hashtags \#visitdaugavpils \#daugavpils \#traveldaugavpils. The profile description contains the name of Daugavpils city in Latvian, Russian and English, as well as a reference to the official website of the municipality.

High quality pictures with reference to the authors of the pictures are used in the Instagram account of the Daugavpils City Council. Most of the pictures are supplemented with a descriptive text in several languages Latvian and English; Latvian and Russian; Latvian, English and Russian; Latvian, Russian, English, Polish and German. Usage of the accompanying texts and the language of the hashtags show that the Daugavpils City Council tries to address local residents, domestic and foreign tourists via Instagram by informing them about the events and most attractive objects in the city. The city of Daugavpils uses the opportunity to place several pictures in one publication.

The Daugavpils City Council also uses the opportunity to publish storytype publications, which are visible to users 24 hours after their publication or later can be found in the archive next to the profile information, where they can be grouped into categories. Eleven categories with titles in English have been created for the city of Daugavpils. The content of story publications consists of publications of events and nature views, including content published by other network users, thus it can be concluded that the administrators of the Daugavpils Instagram profile also monitor Instagram users' content, which helps to understand and address the target audience.

The Daugavpils City Council not only uses the photo placement option in its profile but also actively publishes short video materials from various events and tourist attractions.

The official profile of Daugavpils city is followed by 1923 users, while publications collect on average 60 to 200 likes.

The profile of Rezekne municipality does not have clearly defined a target audience, as well as hashtags are not being used. The profile description refers to the municipality's official website, while the publications are mostly low or medium quality pictures of events or landscapes, as well as event posters that are not specially designed for Instagram in terms of size and quality, so they are not always easy to read.

The publications are accompanied by a text in Latvian, which informs about the event or the tourist attraction shown in the publication. A story's opportunity is not being used and the regularity of publications is not fixed. The last publication on the network was posted on January 15, 2020.

The number of followers of the profile is 869 , but the average number of likes is from 10 to 50 . 


\section{Conclusions and Recommendations}

By summarizing the data, it can be concluded that the regularity of the publications, more complete use of the tools, the official profile's tags in publications and stories provide both a larger number of followers and more feedback in the form of users' comments and likes.

The city of Daugavpils uses hashtags in its Instagram profile, publishes stories, post publications in several languages, as well as uses the geolocation option, thus increasing the possibilities to reach as many users as possible, while Rezekne municipality rarely places publications and do not use additional tools, as a result of which the feedback in the form of comments, likes and the number of followers is smaller than that for Daugavpils city.

Instagram is one of the world's most popular social networks, used by a large number of people around the world, so usage of the right tools is an effective mean for both communication and promoting and strengthening brand values. Municipalities are interested in attracting as many tourists and entrepreneurs as possible, as well as in providing effective feedback to inhabitants, and Instagram is an effective way to do this in an informal way by improving the municipality's public image.

When summarizing the results of the research and drawing conclusions, several recommendations can be put forward that municipalities can use in work with Instagram and social networks:

1. The importance of social networks in corporate communication is growing, so there is a need to hire an individual employee who would work only with social networks.

2. The widest possible range of tools should be used, such as stories, hashtags, geolocation, to address the audience in multiple languages, etc.

3. Define the audiences you work with and customize the tools depending on the message.

4. The content should be updated regularly in order to ensure users' interest.

5. Feedback and interactivity must be provided.

\section{References}

1. Caliandro, A., \& Graham, J. (2020). Studying Instagram Beyond Selfies. Social Media + Society. Retrieved from https://doi.org/10.1177/2056305120924779

2. Goodman, A. (2003). Storytelling as Best Practice: How Stories Strengthen Your Organization, Engage Your Audience, and Advance Your Mission. Los Angeles: A.L., P.

3. Khan, G. F. (2017). Social Media for Government: A Practical Guide to Understanding, Implementing, and Managing Social Media Tools in the Public Sphere. SpringerBriefs in Political Science. Singapore: Springer. 
4. Lim, S., Yazdanifard, R. (2014). How Instagram can be used as a tool in social networking marketing. Center for Southern New Hampshire University (SNHU) ProgramsHELP College of Art and TechnologyKuala Lumpur, Malaysia

5. Neher, K. (2013). Visual Social Media Marketing, first edition. Ohio: Boot Camp Publishing.

6. Tiggemann, M., Zaccardo, M. (2016). 'Strong is the new skinny': A content analysis of \#fitspiration images on Instagram. Journal of Health Psychology. 2018;23(8):1003-1011. P32.

7. Turri, A. M., Smith, K. H. \& Kemp, E. (2013). Developing Affective Brand Commitment through Social Media. Journal of Electronic Commerce Research. 14(3), 205 - 208. 